\title{
Nurse-led telephone consultation and outpatient local anaesthetic abortion: a pilot project
}

\author{
Sandeep Sharma, Kate Guthrie
}

\begin{abstract}
Objectives The study objectives were to improve access to earlier and safer abortion and to offer women a wider choice of method of termination of pregnancy (TOP).

Methods The study comprised two pilot projects conducted in a teaching hospital to assess the feasibility of (1) a telephone booking clinic and (2) a local anaesthetic outpatient surgical termination of pregnancy (LA-STOP) service. The main outcome measures were the uptake of services by referrers and patients, staff acceptability and cost.
\end{abstract}

Results Demand from referrers for the telephone booking clinic was greater than could be accommodated by the service. Telephone consultation was popular with patients as it was carried out at their convenience in their homes, and with staff as it reduced clinic assessment time. Some staff members felt that consulting over the telephone affected their assessment of the patient's emotional status. Outpatient LA-STOP seemed well accepted by both staff and patients as it offered patients a convenient and safe method of early abortion. A preliminary costing indicated a net saving plus increased service capacity.

Conclusions The pilots suggest that the introduction of a telephone booking clinic and LA-STOP service into existing hospital services is feasible and cost effective. Further research is required to evaluate the potential for reducing waiting times and the gestations at which terminations are carried out.

J Fam Plann Reprod Health Care 2006; 32(1): 19-22 (Accepted 23 September 2006)

Key message points
- An initial telephone consultation with a nurse is convenient
for patients and can reduce time spent in the doctor
assessment clinic.
- Surgical termination of pregnancy under local anaesthetic
(LA-STOP) as a hospital outpatient procedure is feasible
and is likely to be acceptable to staff and patients. Demand
for LA-STOP seems sufficient to justify offering women a
choice.
- Telephone consultation clinics and LA-STOP services can
be introduced at no extra cost.
- Mainstream implementation could potentially reduce
referral-procedure times and allow women to undergo
abortion at earlier gestations.

Department of Obstetrics and Gynaecology, Bradford Royal Infirmary, Bradford, UK

Sandeep Sharma, MD, MRCOG, Specialist Registrar in Obstetrics and Gynaecology

Sexual and Reproductive Health Care Partnership, Conifer House, Hull, UK

Kate Guthrie, FRCOG, MFFP, Consultant in Sexual and Reproductive Health

Correspondence to: Dr Sandeep Sharma, Department of

Obstetrics and Gynaecology, Bradford Royal Infirmary,

Duckworth Lane, Bradford BD9 6RJ, UK.

E-mail: dr sandysharma@yahoo.co.uk

\section{Introduction}

The earlier in pregnancy an abortion is performed, the lower the risk of complications. ${ }^{1}$ In 2001, the Department of Health addressed the problem of inequalities in access to abortion services in the National Strategy for Sexual Health and HIV. ${ }^{2}$ This document endorsed the recommendations on waiting time targets set by the Royal College of Obstetricians and Gynaecologists (RCOG) in 2000. ${ }^{1}$ A recent report by the UK fpa (Family Planning Association) shows that by cutting abortion waiting times by 10 days, more women would be eligible for early medical abortion or a surgical abortion under local anaesthesia, making a saving of up to $£ 30$ million per year. ${ }^{3}$

Abortions performed under general anaesthesia are associated with higher complication rates than those performed under local anaesthesia. ${ }^{4,5}$ In the USA between 1972 and 1987, about $20 \%$ of the 240 deaths from legal induced abortion were attributed to anaesthetic complications. ${ }^{6}$ Termination of pregnancy under local anaesthesia is a recognised safe and effective method of early surgical termination. Thonneau et al. confirmed the safety and efficacy of abortion by vacuum aspiration under local anaesthesia. ${ }^{7}$ Manual vacuum aspiration has also been reported to be safe and efficacious by many studies conducted in the USA.$^{8-10}$ A recent pilot study done in the UK has found this to be feasible in the outpatient setting and also acceptable to patients. ${ }^{11}$ Since 2004 , the RCOG guidelines have included the recommendation that the option of local anaesthetic abortion be available, particularly for low-gestation procedures. ${ }^{1}$

In this descriptive study of two pilot projects we aimed to find ways of improving access to earlier and safer abortion, and to offer women more choice of method, by assessing the feasibility of (1) a telephone booking clinic and (2) a local anaesthetic outpatient surgical termination of pregnancy (LA-STOP) service. In addition, we aimed to assess whether mainstream implementation of these changes could be achieved at no extra cost.

\section{Methods}

The pilot studies were conducted at the Women and Children's Hospital, Hull Royal Infirmary, Hull, UK during the period February-March 2004.

\section{Telephone booking clinic}

The woman was instructed to be available by a nominated phone for 3 hours from $4 \mathrm{pm}$ to $7 \mathrm{pm}$ on the designated day. Mobile numbers were also accepted. To maintain confidentiality, the receptionist booking the telephone clinic appointment asked the patient if anyone else might answer the phone and whether that person knew about the pregnancy. The referring clinician faxed a copy of the referral letter and asked the patient to bring the signed HSA $^{1}$ Abortion Act form to the hospital consultation.

The nursing staff for the telephone clinic were drawn from the Gynaecology Day Unit. They were all experienced in dealing with medical and surgical abortions and could answer queries with confidence. The initial part of the local care pathway document, ${ }^{12}$ normally completed in the outpatient pre-assessment clinic, was filled in by the nurse over the telephone. Contraception and sexual health issues were also covered, as were the probable gestation of 
the pregnancy, possible methods of abortion available [medical termination of pregnancy (MTOP), general anaesthetic outpatient surgical termination of pregnancy (GA-STOP) and LA-STOP] and the availability of social workers and counsellors. The woman was given an appointment to come for a scan and doctor assessment visit in the outpatient clinic prior to the termination. Provided there were no confidentiality issues, information leaflets were posted out to the patient.

The exclusion criteria were under 16-year-olds, noncompetent adults, women judged to be more than 10 weeks' gestation at the time of termination, women who required an interpreter, and women who could not guarantee to be available at a confidential phone number during the telephone clinic session.

\section{LA-STOP clinic}

This option was offered at the medical assessment visit. The procedure was carried out in the gynaecology outpatient department minor procedures rooms and was supported by theatre staff. All women had been screened for genital infections at the hospital clinic visit and prophylactic antibiotics were given prior to the procedure. They were also given misoprostol to insert vaginally 3 hours before the procedure. The LA-STOP clinic was conducted by the same doctor every week, thus all procedures were performed by a single operator. Paracervical block was used only when it was deemed necessary to dilate the cervix. Lignocaine $1 \%$ was injected deep into the cervix at 4 and 8 o'clock positions. Manual vacuum aspiration was used instead of the electric suction machine to avoid the noise associated with the latter. An oxytocic was not routinely used nor was sharp curettage. Anti-D immunoglobulin G 250 IU was given to Rhesus Dnegative women following the abortion and contraceptive supplies plus condoms were provided. If chosen, intrauterine contraceptive devices/systems, contraceptive injections or implants could also be fitted at the same visit. The patients were offered a hot drink and were observed for about 30 minutes before being allowed to go home. They were advised not to drive home and to bring a companion to escort them home.

The exclusion criteria were as for the telephone clinic (except being available for telephone contact).

\section{Outcome measures}

During the pilot we noted the number of referrals to the telephone clinic, the number of telephone consultations and the number of women undergoing LA-STOP. Attendance rates were compared with those of women referred and treated by standard pathways. Staff involved in each of the arms of the project were asked to complete an anonymous questionnaire which sought their views on various aspects of the clinics. Using figures obtained from the Trust Finance Department, we estimated the cost of running clinics and the LA-STOP service during the pilot period compared with the cost of standard services.

\section{Results}

\section{Telephone booking clinic}

The telephone booking clinic was popular with general practitioners (GPs) and they soon began asking for the telephone clinic on behalf of their patients. Indeed, some GPs were disappointed if their patients could not be assessed by this method. A total of 58 patients were booked, though five subsequently failed to attend the doctor clinic, giving a $91.4 \%$ attendance rate. During the same time period, $10 / 160$ patients did not attend the standard abortion clinics, giving an attendance rate of
Table 1 Responses to staff questionnaire

\begin{tabular}{|c|c|c|c|}
\hline Question & Yes & No & $\begin{array}{l}\text { No } \\
\text { response }\end{array}$ \\
\hline \multicolumn{4}{|l|}{$\begin{array}{l}\text { Telephone booking clinic/doctors pre-assessment } \\
\text { clinic }\end{array}$} \\
\hline Were you satisfied with the conduct of the clinics? & 12 & 2 & - \\
\hline $\begin{array}{l}\text { Do you think the patients were satisfied with this } \\
\text { service? }\end{array}$ & 14 & - & - \\
\hline $\begin{array}{l}\text { Do you think this should be started on a regular } \\
\text { basis? }\end{array}$ & 11 & 1 & 2 \\
\hline \multicolumn{4}{|l|}{$\begin{array}{l}\text { Local anaesthesia surgical termination of pregnancy } \\
\text { clinic }\end{array}$} \\
\hline Were you satisfied with the conduct of the clinics? & 13 & 1 & - \\
\hline $\begin{array}{l}\text { Do you think the patients were satisfied with this } \\
\text { service? }\end{array}$ & 13 & - & 1 \\
\hline $\begin{array}{l}\text { Do you think this should be started on a regular } \\
\text { basis? }\end{array}$ & 13 & - & 1 \\
\hline
\end{tabular}

93.75\%. Telephone consultations took approximately 30 minutes per patient including all paperwork.

\section{LA-STOP clinic}

A total of 12 patients underwent TOP under local anaesthesia and there were no cancellations. Of these 12 women, six were booked in through the regular clinics and six through the telephone-initiated clinics. During the same time period (February-March 2004), 13/163 (8\%) patients did not attend their appointment for the GA-STOP. In February-March 2003, 11/148 (7\%) STOP patients did not attend. All patients were observed for at least 30 minutes after the procedure and left the outpatient department within 45 minutes.

\section{Staff acceptability questionnaire}

All 23 members of staff responded (a 100\% response rate). Some of the outpatient staff had worked in both the doctor assessment clinic and LA-STOP clinic whilst some were associated only with one of them, which is why Table 1 shows responses from 14 in each group. The majority of staff members were satisfied with the conduct of both arms of the pilot. Their impression was that all patients were

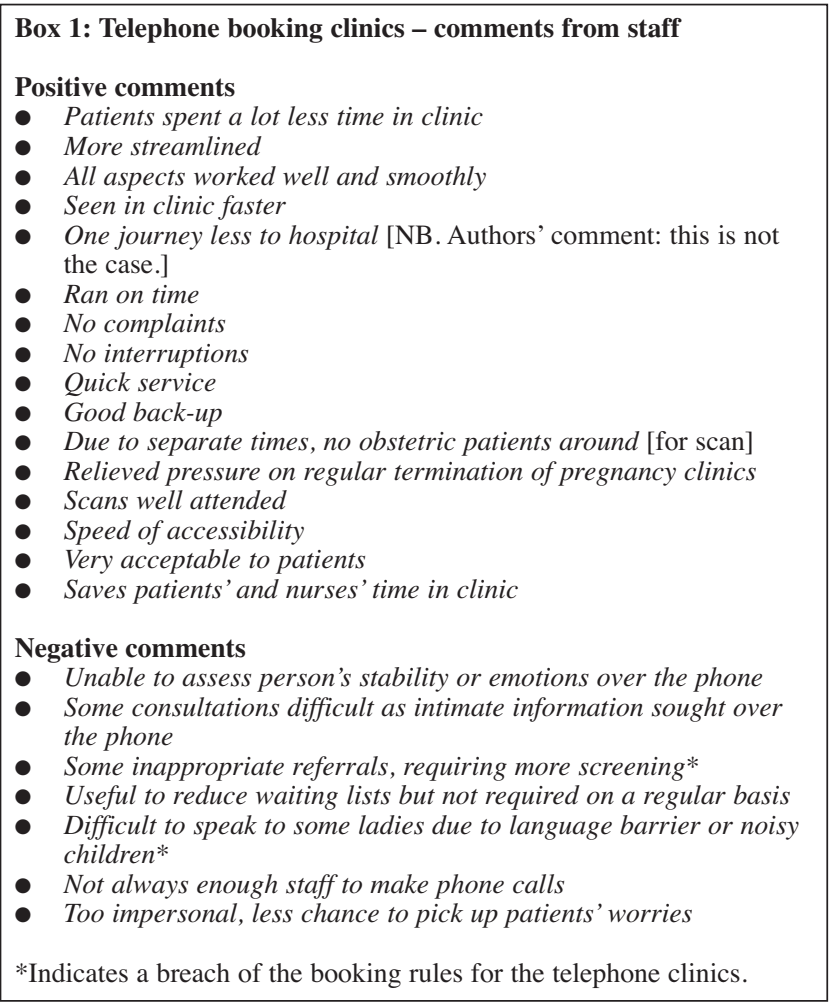


Box 2: Local anaesthesia surgical termination of pregnancy clinic - comments from staff

Positive comments

- Patients in and out of clinic in 1 hour

- Received contraception at the same time

- Avoids general anaesthetic [two respondents]

- Reduces impact on theatre sessions

- Speed of procedure

- Helpful to reduce waiting lists for the service

- Less risk, less traumatic than medical termination of pregnancy

- Patients all thought it was great, had no after effects and went home after a drink

- Offers women more choice, fast recovery, not dependent on theatres

- Despite going through a traumatic procedure, patients did not appear very distraught and were appreciative of the reassurance and support given during the procedure and could go home straight away

- Lady seemed relaxed

- People fear general anaesthetic and this offers them a choice

- Better service for patients as general anaesthetic not required, quicker recovery

- More informal surroundings, did not feel rushed

- Relaxed atmosphere, relatives nearby

Negative comment

- I think patients need longer to recover as some patients looked quite ill on leaving clinic* $^{*}$

*This negative comment was given by one of the 'satisfied' members of staff.

satisfied with these clinics. One staff member in the LASTOP clinic did not respond to the question. Comments received from staff are shown in Boxes 1 and 2. Only one staff member from the LA-STOP clinic was dissatisfied but declined to give any comment.

\section{Costing}

Currently approximately 32 patients are seen per week across five outpatient clinics. Substituting two doctor assessment clinics of 10 patients for two clinics of six patients, supported by 2.5 nurse telephone clinics, would increase the service capacity by eight patients per week (i.e. an $25 \%$ increase).

The present cost of a MTOP or a STOP (day case) ranges from $£ 462$ to $£ 578$ per patient. The outpatient LASTOP clinic as part of this pilot project, however, cost $£ 366$ per patient (Table 2). The present cost per outpatient consultation comes to $£ 217$ per patient (Finance Department, Hull and East Yorkshire NHS Trust, personal communication). This could be reduced to $£ 177$ if the nurse telephone clinic was used to reduce the time needed by the doctor to assess each patient, thus increasing the number of patients per clinic. This costing indicates that both the alternative methods of outpatient consultation and LASTOP were marginally less expensive than the current mainstream services (Table 3).

Table 2 Details of staff required for each clinic type for costing purposes

\begin{tabular}{ll}
\hline Type of clinic & Staff \\
\hline Telephone clinic & $1 \times$ E Grade nurse \\
& $1 \times$ AC2 support \\
TOP outpatient clinic & $1 \times$ doctor \\
& $2 \times$ E Grade nurses \\
& $1 \times$ A Grade nurse \\
& $1 \times$ AC2 reception \\
& $1 \times$ stenographer \\
& $1 \times$ stenographer helper \\
& $1 \times$ doctor \\
& $1 \times$ F Grade nurse \\
& $2 \times$ E Grade nurses \\
& $2 \times$ A Grade nurses
\end{tabular}

LA-STOP, local anaesthetic surgical termination of pregnancy.
Table 3 Full costs of the various termination of pregnancy procedures (including all Trust overheads and laboratory tests/scans)

\begin{tabular}{ll} 
Procedure & Cost per patient \\
\hline $\begin{array}{ll}\text { Surgical termination of pregnancy (day case) } \\
\text { Medical termination of pregnancy (outpatient) }\end{array}$ & $£ 482$ or $£ 578$ \\
$\begin{array}{l}\text { Local anaesthetic surgical termination of pregnancy } \\
\text { (pilot) }\end{array}$ & $£ 366$ \\
$\begin{array}{l}\text { Current cost per outpatient consultation (two clinics } \\
\text { with six patients per clinic) }\end{array}$ & $£ 217$ \\
$\begin{array}{l}\text { Pilot projected cost (two clinics each with 10 patients } \\
\text { per doctor's clinic and 2.5 nurse telephone clinics }\end{array}$ & $£ 177$ \\
$\begin{array}{l}\text { with 10 patients per clinic) } \\
\end{array}$ &
\end{tabular}

\section{Discussion}

\section{Telephone booking clinic}

The telephone consultation was thought to be more convenient for the patients as they could be contacted in the comfort of their home or at another venue of their choice.

With telephone assessment, patients suitable for MTOP can be prioritised to be seen in the medical clinic early enough to get maximum capacity out of the MTOP service. More patients could be offered the choice of first-trimester MTOP rather than surgery if they are seen early enough. Fast tracking could also be used to reduce the number of abortions that have to be outsourced for mid-trimester procedures not available locally.

Due to funding limits, only one telephone clinic, one supporting doctor assessment clinic and one LA-STOP procedure clinic were possible per week. This led to the time intervals between the telephone clinic/doctor clinic and doctor clinic/LA-STOP being fixed. If the service adopted more telephone clinics per week then a reduction in the referral/procedure interval would be achievable due to increased clinic capacity.

\section{LA-STOP clinic}

All patients who underwent abortion under local anaesthesia spent 2 hours or less within the hospital. In comparison, patients who have the GA-STOP procedure spend between 6 and 8 hours in hospital. There was also less dependence on operating theatre space, as the procedure was done in the outpatient minor procedures room. There were no absentees from the LA-STOP clinic. This could be due to the high level of patient motivation for accepting the local anaesthesia. However, the numbers are too small to attach any statistical significance to this finding. As a pilot process, this study can be criticised for not formally evaluating patient satisfaction. However, the positive response of the nurses and other staff in the service suggests that, pending formal evaluation, patients were satisfied.

A preliminary costing indicated that the cost per case for both outpatient consultation and LA-STOP is less than the current costs for both pre-assessment and standard TOP procedure. As the duration of the pilot was short, it was not possible to see an effect on mid-trimester TOPs which are usually outsourced. However, this too is a potential area for reducing costs. Reduced dependence on operating theatres and staff is of further benefit.

\section{Conclusions}

Both the telephone booking clinic and LA-STOP service proved feasible and acceptable to staff. The interventions were seen as offering women more choice and more convenience. There is also the potential benefit of reducing the referral/procedure waiting time, and therefore the gestations at which terminations are carried out. The pilot was costed at being slightly less expensive than the current service. 


\section{ARTICLE/JOURNAL REVIEW}

\section{Acknowledgements}

The authors express their sincere gratitude to the staff of the Women and Children's Hospital who tirelessly support all initiatives enhancing women's health care across Hull and East Yorkshire.

\section{Statements on funding and competing interests}

Funding. The pilot project was funded by four local primary care trusts through joint commissioning.

Competing interests. None identified.

References

1 Royal College of Obstetricians and Gynaecologists (RCOG). The Care of Women Requesting Induced Abortion (National EvidenceBased Clinical Guideline No. 7). London, UK: RCOG Press, 2004.

2 Department of Health. National Strategy for Sexual Health and HIV. London, UK: Department of Health, 2001.

3 The 'Economics of Sexual Health' research by Newcastle University, commissioned by fpa. 2005. http://www.fpa.org.uk/news/policy/PDFs/ Theeconomicsofsexualhealth.pdf [Accessed 19 September 2005]

4 Mackay HT, Schulz KF, Grimes DA. Safety of local versus general anaesthesia for second trimester dilatation and evacuation abortion. Obstet Gynecol 1985; 66: 661-665.

5 Grimes DA, Schulz KF, Cates W Jr, Tyler CW. Local versus general anaesthesia: which is safer for performing suction curettage abortion. Am J Obstet Gynecol 1979; 135: 1030-1035.

6 Lawson HW, Frye A, Atrash HK, Smith JC, Shulman HB, Ramick M. Abortion mortality, United States, 1972 through 1987. Am J Obstet Gynaecol 1994; 171: 1365-1372.

7 Thonneau P, Fougeyrollas B, Ducot B, Boubilley D, Dif J, Lalande $\mathrm{M}$, et al. Complications of abortion performed under local anesthesia. Eur J Obstet Gynecol Reprod Biol 1998; 81: 59-63.

8 Edward J, Creinin MD. Early abortion: surgical and medical options. Curr Prob Obstet Gynecol Fertil 1997; 20: 6-32.

9 Westfall JM, Sophocles A, Burggraf H, Ellis S. Manual vacuum aspiration for first-trimester abortion. Arch Fam Med 1998; 7: $559-562$.

10 Dean G, Cardenas L, Darney P, Goldberg A. Acceptability of manual versus electric aspiration for first trimester abortion: a randomized trial. Contraception 2003; 67: 201-206.

11 Hamoda H, Flett GM, Ashok AW, Templeton A. Surgical abortion using manual vacuum aspiration under local anaesthesia: a pilot study of feasibility and women's acceptability. J Fam Plann Reprod Health Care 2005; 31: 185-188.

12 Guthrie K, Waudby C, Arnott P. A termination of pregnancy care pathway: worth the effort? Eur J Contracept Reprod Health Care 2004; 9: 38 .

\section{Journal Review}

Efficacy of a new low-dose oral contraceptive with drospirenone in premenstrual dysphoric disorder. Yonkers KA, Brown C, Pearlstein TB, Foegh M, Sampson-Landers C, Rapkin A. Obstet Gynecol 2005; 106: 492-501

This multicentre, double-blinded, randomised, placebo-controlled trial in the USA aimed to assess the effect of a 24/4 regimen of drospirenone $3 \mathrm{mg}$ and ethinylestradiol $20 \mu \mathrm{g}$ on symptoms associated with premenstrual dysphoric disorder.

A total of 3496 women were recruited via advertisement and referral, with 450 being blindly randomised to receive either placebo or drospirenone/ethinylestradiol therapy over a 3month period. A high proportion of initially selected patients either discontinued the study prematurely or did not meet inclusion criteria. Seventy-one patients in the treatment group discontinued the study prematurely with over half complaining of adverse drug events. These included intermenstrual bleeding, headache and nausea.

Response to therapy was measured by daily self-assessment using the Daily Record of Severity of Problems Scale. Data were analysed from the intent-to-treat cohort that included all randomised subjects who took at least one treatment dose. Response to treatment was defined as a $50 \%$ reduction in daily symptom score. This occurred in $48 \%$ of the active treatment group and $36 \%$ of the placebo group (RR 1.7). This was significant at the $p<0.05$ level but not at $p<0.01$. This corresponded to a number-needed-to-treat of eight patients.

Although the results suggest that this new low-dose 24/4 regimen of drospirenone $3 \mathrm{mg}$ and ethinylestradiol $20 \mu \mathrm{g}$ is beneficial in symptom amelioration in premenstrual dysphoric disorder, a comparison was not made with either a standard combined oral contraceptive pill or with the currently marketed $21 / 7$ regimen of drospirenone $3 \mathrm{mg}$ and ethinylestradiol $30 \mu \mathrm{g}$ (under the trade name of Yasmin ${ }^{\circledR}$ ). The study was funded by the pharmaceutical company that supplies the trial drug, and two of the authors were employees of the company.

The cost effectiveness of low-dose drospirenone and ethinylestradiol therapy has yet to be evaluated and its relative efficacy compared to current treatment will need to be proven before such treatment becomes commonplace in the UK.

Reviewed by Karen Rose, MB ChB

Senior House Officer, Dean Terrace Family Planning Clinic, Edinburgh, UK

Impact on contraceptive practice of making emergency hormonal contraception available over the counter in Great Britain: repeated cross-sectional surveys. Marston C, Meltzer H, Majeed A. BMJ 2005; 331: 271-275

This paper compares data on contraceptive practice among 16-49-year-old women over 3 years from 2000 to 2002. Approximately 2000 women were surveyed each year as part of the Omnibus multipurpose survey. Women were selected by random sampling of addresses and occupants throughout the UK. Interviewers asked about use of contraceptives and emergency hormonal contraception (EHC).

The most striking change was the source of emergency contraception. The introduction of over-the-counter (OTC) EHC in January 2001 resulted in a marked increase in the proportion of women obtaining EHC from pharmacies (19.7\% in 2001 and $32.6 \%$ in 2002). There was a corresponding reduction in the proportion supplied from general practice and family planning clinics but little change in supply from emergency departments. Women who bought OTC EHC tended to be older, wealthier and single. Over the same period, the proportion of women using emergency contraception once or more than once a year remained static at approximately $6 \%$ and $2 \%$, respectively. There was no significant change in the proportion using reliable contraceptive methods or having unprotected intercourse. The authors conclude that availability of OTC EHC has not led to increased use or encouraged unsafe sex.

The survey did not determine the absolute number of times EHC was used and it excluded women under the age of 16 years. Although the authors attempted to correct for selection bias, they were unable to correct for non-response and recall bias. It was assumed that all EHC obtained from pharmacies was bought, with no mention of free supply under patient group direction. Thus the effect of OTC availability may have been underestimated. The study by Lloyd and Gale in the October 2005 issue of this journal showed an ncrease in EHC use in a rural setting since it became available OTC.

The impact on numbers of unplanned pregnancies is unknown, but OTC EHC does at least appear to be saving health service time and resources.

Lloyd K, Gale E. Provision of emergency hormonal area. J Fam Plann Reprod Health Care 2005; 31: 297-300.

Reviewed by Louise Melvin, MRCOG, DFFP Specialist Registrar, Simpson's Centre for Reproductive Health, Edinburgh, UK

Bleeding patterns after immediate initiation of an oral compared with a vaginal hormonal contraceptive. Westhoff C, Osborne LM, Schafer JE, Morroni C. Obstet Gynecol 2005; 106: 89-96

This study compared 84-day bleeding patterns of 201 women randomly assigned to immediate start ('Quick Start') of a triphasic oral contraceptive pill (25 $\mu \mathrm{g}$ ethinylestradiol) compared with the contraceptive vaginal ring (providing $15 \mu \mathrm{g}$ ethinylestradiol daily). The women either took their first pill or were fitted with a contraceptive vaginal ring irrespective of where they were in their cycle. They then used barrier contraception for the first 7 days and were asked to record their bleeding patterns on a daily basis. The mean bleeding-spotting days in the 84-day reference period for all women was 19.2 days (17.0 days for ring users and 21.4 days for pill users). As well as confirming the excellent bleeding pattern results found in earlier non-randomised studies for the contraceptive vaginal ring, this study also showed that the 'Quick Start' approach is an acceptable alternative to waiting for menses for both contraceptive methods. This is an important observation as this method is easy to implement, increases initiation and may increase effective use and continuation of contraception. Perhaps we should completely abandon the conventional advice we give to women about starting hormonal contraception 'after your next period'?

Reviewed by Andrew Horne, PhD, MRCOC AAGL Clinical Fellow in Gynaecological Endoscopy, Sunnybrook and Women's College Health Sciences Centre, Toronto, Canada 